\title{
Pulmonary Endotoxin Tolerance Protects against Cockroach Allergen-Induced Asthma-Like Inflammation in a Mouse Model
}

\author{
Sudha Natarajan ${ }^{\mathrm{a}}$ Jiyoun Kim ${ }^{\mathrm{a}}$ Jacqueline Bouchard ${ }^{\mathrm{a}} \quad$ William Cruikshank $^{\mathrm{b}}$ \\ Daniel G. Remick ${ }^{a}$ \\ a Department of Pathology and Laboratory Medicine, and ${ }^{b}$ Pulmonary Center, Boston University School of \\ Medicine, Boston, Mass., USA
}

\section{Key Words}

Lipopolysaccharide $\cdot$ Tolerance $\cdot$ Cockroach allergen •

Airway hyperresponsiveness $\cdot$ Cytokines $\cdot \lg \mathrm{E}$

\begin{abstract}
Background: Compounds which activate the innate immune system, such as lipopolysaccharide, are significant components of ambient air, and extremely difficult to remove from the environment. It is currently unclear how prior inhalation of endotoxin affects allergen sensitization. We examined whether lung-specific endotoxin tolerance induction prior to sensitization can modulate the response to allergen. Methods: Endotoxin tolerance was induced by repeated intratracheal exposure to endotoxin. All mice were then sensitized and challenged by direct intratracheal instillation of cockroach allergen. Results: After allergen sensitization and challenge, endotoxin tolerant mice had significantly decreased airways hyperresponsiveness to methacholine challenge, which was confirmed by invasive lung function tests. Decreased goblet cell hyperplasia and mucus production were also found by histological assessment. Tolerant mice were protected from airway eosinophilia through the mechanism of reduced CCL11 and CCL24. Interestingly, endotoxin tolerant mice had only a modest reduction in
\end{abstract}

cockroach-specific lgE; however, total IgE was significantly reduced. Conclusions: These data show that induction of endotoxin tolerance prior to sensitization protects against the hallmark features of asthma-like inflammation, and that transient modulation of innate immunity can have long-lasting effects on adaptive responses.

Copyright $\odot 2012$ S. Karger AG, Basel

\section{Introduction}

Asthma is a chronic inflammatory disease characterized by three hallmark features: bronchial hyperresponsiveness, airway eosinophilia and IgE production [1]. It is also widely understood that innate immune activating factors, particularly signaling through the Toll-like receptor (TLR) ligands, influence asthma severity [2]. Inhalation of high-dose lipopolysaccharide (LPS), concomitant with allergen sensitization has been shown to protect against the development of allergy [3]. While the exact mechanisms dictating this immune modulation are not known, it is generally accepted that the role LPS plays in asthma severity depends on the dose and timing of exposure [4]. This is further highlighted by the hygiene hypothesis, which asserts that early exposure to

\section{KARGER}

Fax +41613061234 E-Mail karger@karger.ch www.karger.com (c) 2012 S. Karger AG, Basel

$1018-2438 / 12 / 1582-0120 \$ 38.00 / 0$

Accessible online at:

www.karger.com/iaa
Correspondence to: Dr. Daniel G. Remick

Department of Pathology and Laboratory Medicine

Boston University School of Medicine, Room 407, 670 Albany Street

Boston, MA 02118 (USA)

Tel. +1 617414 7043, E-Mail remickd@ bu.edu 
high levels of innate immune activating compounds can protect against the onset of atopy, while lack of exposure can increase the risk of developing allergic diseases $[5,6]$. This has been postulated as an underlying cause for increased asthma incidence and severity in developed countries. Additionally, the incidence and severity of asthma in inner city children is far greater than that seen in children raised in farming environments, and the levels of LPS present in farm environments are significantly higher than those measured in inner city homes $[7,8]$. We sought to investigate pulmonary LPS tolerance as a mechanism responsible for attenuated asthma severity in response to cockroach allergen (CRA) sensitization and challenge.

Repeated exposure to LPS can induce a transitory state of LPS hyporesponsiveness [9]. This phenomenon has recently been identified as a unique mechanism by which the lung protects itself from excessive inflammation, by attenuating $\mathrm{TNF} \alpha$, and $\mathrm{CXC}$ chemokine production, while maintaining the capacity to recruit neutrophils and thus fight bacterial challenge $[10,11]$. In this study, we employed a novel model combining LPS tolerance and asthma induction to determine how repeated LPS inhalation affects the adaptive response. We used a clinically relevant model of intratracheal allergen sensitization without the use of adjuvants. Given the ubiquitous presence of LPS in the environment, understanding its role in the onset and progression of allergic diseases is essential in determining effective treatment methods.

\section{Materials and Methods}

\section{Animals}

Female BALB/c mice, 9-12 weeks old, were purchased from Jackson Laboratories (Bar Harbor, Me., USA), and maintained under standard laboratory conditions. The mice were housed in a temperature- and humidity-controlled room with 12-hour light/ dark cycles and were allowed food and water ad libitum. All experiments were performed according to the National Institutes of Health guidelines and were approved by the Boston University Institutional Animal Care and Use Committee.

\section{Induction of LPS Tolerance and Asthma-Like Pulmonary} Inflammation

LPS tolerance was induced by exposing mice to $1 \mu \mathrm{g}$ LPS ( $E$. coli LPS O111:B4, Sigma-Aldrich-62325) in a total volume of $50 \mu \mathrm{l}$ sterile PBS once daily during days -4 to -1 , by direct intratracheal instillation, as previously described. Nontolerant mice received $50 \mu \mathrm{l}$ sterile PBS [12]. On day 0 , all mice were sensitized to cockroach allergen (CRA) by intratracheal administration of $2 \mu \mathrm{g}$ CRA (Greer Laboratories, LeNoir, NC, Item \# B46) in $50 \mu \mathrm{l}$ PBS. No adjuvants were used for asthma induction. On day 14 , mice were challenged intratracheally with $1 \mu \mathrm{g}$ CRA, and received the same challenge on day 21. This CRA preparation contained 200 ng LPS contamination for sensitization and $100 \mathrm{ng}$ LPS at challenge as determined by Limulus amoebocyte lysate assay [10]. Airways hyperresponsiveness and airway resistance were measured and animals were sacrificed at various timepoints as indicated in the figure legends. The $0 \mathrm{~h}$ timepoint represents sacrifice immediately prior to receiving the day 21 CRA challenge.

\section{Airways Hyperresponsiveness}

Airways hyperresponsiveness was measured using unrestrained whole-body plethysmography (Buxco Systems, Troy, N.Y., USA). Mice were placed in the instrument chamber and allowed to acclimate for $5 \mathrm{~min}$ and baseline measurements were then recorded for $5 \mathrm{~min}$. Next, mice were challenged for $2 \mathrm{~min}$ with aerosolized PBS, followed by increasing doses of methacholine (Sigma, St. Louis, Mo., USA). Each aerosol was followed immediately by $5 \mathrm{~min}$ of data collection. The partial pressure difference between the experimental and a reference chamber is represented as the PenH parameter. This has been shown to correlate closely with invasive measurements, and has been used in several high-impact publications [13-15]. The data is represented as the percent increase in PenH above baseline.

\section{Airway Resistance}

Whole-body plethysmography data were further verified using invasive pulmonary function tests. For measurement of mouse airway resistance, mice were anesthetized with an i.p. injection of 1:5 diluted pentobarbital (Nembutal ${ }^{\circledR}, 0.016 \mathrm{ml} / \mathrm{g}$ body weight, Ovation Pharmaceutical, Deerfield, Ill., USA). The paralytic was pancuronium (Sigma-Aldrich, St. Louis, Mo., USA) at $0.5 \mu \mathrm{g} / \mathrm{g}$ body weight. Adequate surgical sedation was determined by a firm squeeze of the foot pad. A tracheotomy was then performed by insertion of an 18-gauge polyethylene cannula into the distal trachea. The mouse was placed on the FlexiVent mechanical ventilator (Scireq Scientific Respiratory Equipment, Montreal, Canada) and ventilated at 190 breaths per minute with positive end-expiratory pressure set at $3 \mathrm{~cm} \mathrm{H}_{2} \mathrm{O}$. Airway resistance measurements in response to increasing concentrations of aerosolized methacholine were obtained through periodic computer-generated 'snapshot 150' forced-maneuver interruptions in ventilation. Data are presented as resistance change from baseline $\left(\mathrm{cm} \mathrm{H}_{2} \mathrm{O}\right.$ per milliliter per second).

Bronchoalveolar Lavage and Lung Homogenate Preparation

Mice were exsanguinated and bronchoalveolar lavage (BAL) was performed by cannulating the trachea. The lung was lavaged with two 1-ml aliquots of warm Hanks' balanced salt solution (HBSS, Gibco, Grand Island, N.Y., USA). Both aliquots were centrifuged and the supernatant of the first wash was removed and frozen at $-20^{\circ} \mathrm{C}$ for cytokine analysis. The supernatant from the second wash was discarded and the cell pellets from both aliquots were combined. Total cell counts were obtained using a BeckmanCoulter particle counter model ZF (Coulter Electronics Inc., Hialeah, Fla., USA). Cytospin preparations were stained with DiffQuick and 300 cell differential counts were performed to determine the absolute numbers of inflammatory cells. The right lung was removed, placed in ice-cold protease inhibitor cocktail (Roche, Indianapolis, Ind., USA) containing $0.00005 \%$ Triton $\mathrm{X}-100$ in PBS, and homogenized with three 10 -second passes in a 
Brinkmann Polytron PT3000 homogenizer. An aliquot was removed and sonicated in $0.5 \%$ cetyltrimethylammoniumchloride (CTAC) (Sigma) for eosinophil-specific peroxidase assay [16]. The homogenized and sonicated mixtures were centrifuged at 15,000 $g$ for $15 \mathrm{~min}$. The homogenate supernatant was removed and stored at $-20^{\circ} \mathrm{C}$ for cytokine analysis and the supernatant from the sonicated fractions was used immediately for peroxidase assay.

\section{Eosinophil Peroxidase Assay}

Eosinophil peroxidase (EPO) assay was performed as described previously, with some modifications [16]. Supernatants of the mixture sonicated in CTAC were diluted 1:3 in $10 \mathrm{mM}$ HEPES, $\mathrm{pH} 8$, in quadruplicate in a 96-well plate. $150 \mu \mathrm{l}$ ice-cold stop solution ( $4 \mathrm{~N} \mathrm{H}_{2} \mathrm{SO}_{4}+2 \mathrm{mM}$ resorcinol) was added to two of the sample wells. $75 \mu \mathrm{l}$ substrate solution containing $6 \mathrm{mM} \mathrm{KBr}, 1.5$ mM o-phenylenediamine (Sigma, St. Louis, Mo., USA, P9029), and $0.3 \% \mathrm{H}_{2} \mathrm{O}_{2}$ in $50 \mathrm{~mm}$ HEPES, $\mathrm{pH} 8$, was added to the two remaining sample wells. The reaction was incubated in the dark for 30 s. $150 \mu \mathrm{l}$ ice-cold stop solution was added and the absorbance was read at $490 \mathrm{~nm}$.

\section{ELISA}

Cytokines, chemokines and antibodies were measured by sandwich ELISA as previously described [17]. Antibody pairs and recombinant standards were purchased from R\&D Systems (Minneapolis, Minn., USA). 20\% normal lung homogenate was added to the standards when assaying lung homogenate samples to adjust for increased background caused by nonspecific matrix effects. ELISAs for measuring antibodies were performed by the same standard protocols with reagents purchased from Bethyl Laboratories (Montgomery, Tex., USA). Cockroach allergen ELISAs were performed as previously described with antibody pairs and recombinant standards from Indoor Biotechnologies (Charlottesville, Va., USA) [18].

\section{Cysteinyl-Leukotriene Immunoassay}

Cysteinyl leukotriene levels in the BAL fluid were measured by a commercially available Enzyme-linked Immunoassay Kit (Cayman Chemicals, Ann Arbor, Mich., USA) according to the manufacturer's instructions. All samples were run at two dilutions, and only $\% \mathrm{~B} / \mathrm{B}_{0}$ values in the linear range of the standard were accepted. $\% \mathrm{~B} / \mathrm{B}_{0}$ values falling out of this range were rerun at an appropriate dilution.

\section{Histopathology}

Immediately after collection of the left lung, the right lung was harvested, fixed in $70 \%$ ethanol, paraffin embedded and processed for routine histology. Separate sections were also stained with periodic acid-Schiff reagent and were examined under a light microscope [19]. Digital images of the entire section were taken and analyzed using NIH ImageJ Software. The outline of each figure was traced and the total area in pixels was calculated using the measure function. Positive PAS staining was selected using the Color Deconvolution plug-in. The area of positive staining was measured using the measure feature. Positive staining is represented as area of PAS staining per $10^{6}$ pixels.

Congo Red Stain for Tissue Eosinophils

Paraffin sections were stained with Congo red as previously described [20]. Eosinophils were counted in a blinded manner in four randomly selected high-powered fields for each section and 8 sections per group were analyzed. Eosinophil numbers are represented as number of eosinophils per high-power field.

Statistical Analysis

All data are represented as mean \pm SEM. Statistical significance was determined by unpaired Student's t test using GraphPad Prism version 4.0.3 (GraphPad Software, San Diego, Calif., USA). Statistical significance was achieved when $\mathrm{p}<0.05$.

\section{Results}

\section{Activation of Innate Immunity after Allergen \\ Sensitization and Challenge}

LPS tolerance was induced by direct intratracheal instillation of LPS for four consecutive days. Both allergen sensitization and challenge were also carried out by intratracheal exposure without the use of adjuvants. Because adjuvants are thought to artificially skew the immune system toward a Th2 response, their use is controversial [21]. By using a clinically relevant allergen and the natural route of exposure, the model used in the current study more accurately recapitulates the clinical setting.

Previous studies of LPS tolerance have defined it as a transient phenomenon. It is generally accepted that if more than 72-96 h elapses between initial LPS exposure and rechallenge, the acute inflammatory response is not attenuated [22-24]. Twenty-four hours after LPS tolerance induction, mice were sensitized with CRA and challenged with CRA on days 14 and 21. Figure 1 shows that LPS tolerance has no lasting effect on the mediators of innate immunity measured here. No difference in neutrophil numbers or concentrations of the CXC chemokines KC (CXCL1) and MIP-2 (CXCL2) in the BAL fluid was observed. More importantly, we saw no lasting defect in the ability of LPS-tolerant mice to produce $\mathrm{TNF} \alpha$ (fig. 1d). Interestingly, LPS-tolerant mice produced more $\mathrm{TNF} \alpha$ in response to allergen challenge.

\section{Pulmonary Function Tests and Mediators of AHR}

We next examined whether LPS tolerance can modulate AHR in response to allergen sensitization and challenge. Mice were exposed to increasing doses of aerosolized methacholine at $4 \mathrm{~h}$ after final allergen challenge. Our laboratory routinely observes robust AHR at this timepoint. LPS-tolerant mice had significantly attenuated AHR compared to nontolerant mice in response to 50 $\mathrm{mg} / \mathrm{ml}$ methacholine (fig. 2a). Although the relevance of whole-body plethysmography has been demonstrated recently, the correlation of PenH to airway function is still 
Fig. 1. Neutrophil numbers and mediators of innate immunity after final allergen challenge. Cytospin preparations from cells collected in the BAL fluid were made and 300 cell differential counts performed to determine the absolute numbers of neutrophils (a). Concentrations of chemokines CXCL1 (b), CXCL2 (c) and TNF $\alpha$ (d) in the BAL fluid were measured by standard ELISA. Data are presented as mean \pm SEM ( $n=4$ mice per group per experiment; combination of 3 separate experiments).

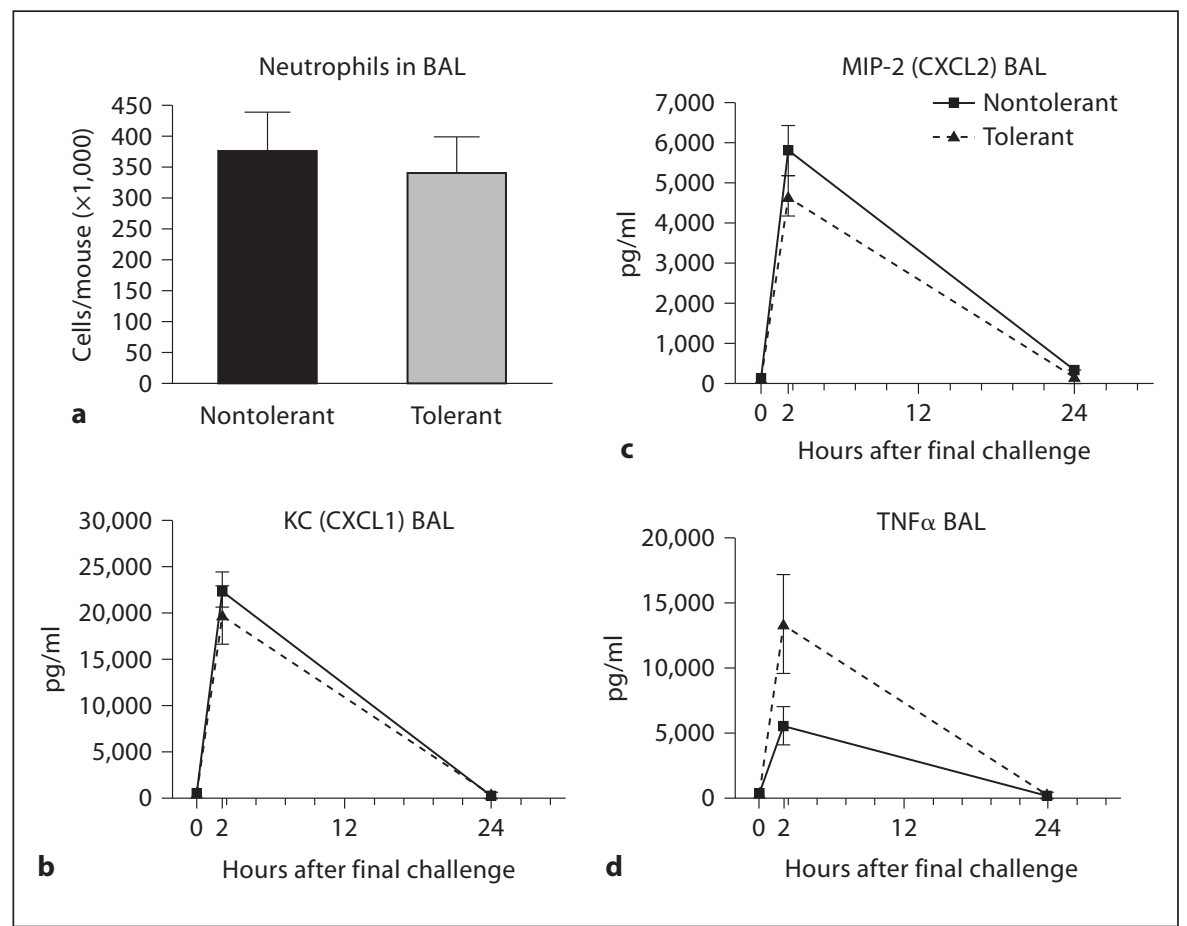

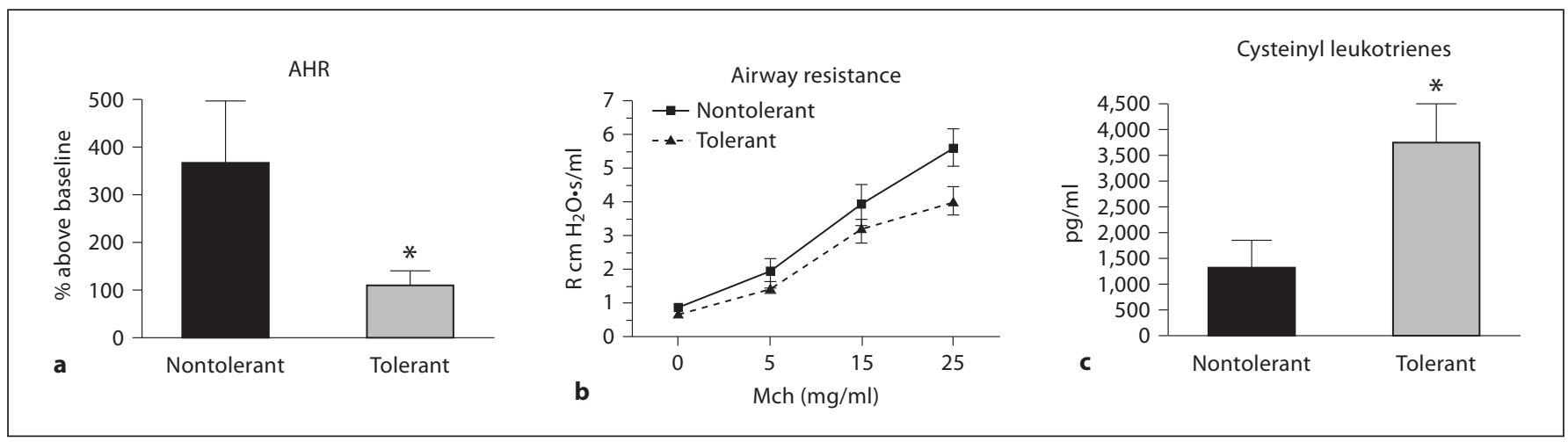

Fig. 2. Measurement of airways hyperresponsiveness, airway resistance and cysteinyl leukotrienes after final allergen challenge. a For unrestrained, whole-body plethysmography, mice were challenged with increasing concentrations of aerosolized methacholine at $4 \mathrm{~h}$ after the final challenge and $\mathrm{PenH}$ values are represented as percent above baseline. b For invasive measurements, mice were challenged with methacholine, as described in 'Materials and

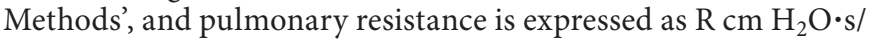
$\mathrm{ml}$. c Cysteinyl leukotrienes were measured in the BAL fluid $2 \mathrm{~h}$ after final challenge. Data are presented as mean \pm SEM. Experiments were done a minimum of 3 times with 3-4 mice per group, per experiment. ${ }^{*} \mathrm{p}<0.05$ compared to nontolerant group. controversial [25]. Therefore, we also verified these findings using invasive pulmonary function tests. Invasive tests demonstrated a trend toward decreased lung function in LPS-tolerant mice after administration of $25 \mathrm{mg} /$ $\mathrm{ml}$ methacholine, confirming the AHR data (fig. 2b). We were unable to administer higher doses of methacholine directly to the trachea due to technical limitations of the assay. We then measured cysteinyl leukotrienes in the BAL fluid at $2 \mathrm{~h}$ after final challenge as a possible mechanism responsible for the decreased airway resistance. Interestingly, cysteinyl leukotriene production was significantly increased in LPS-tolerant mice, suggesting that 

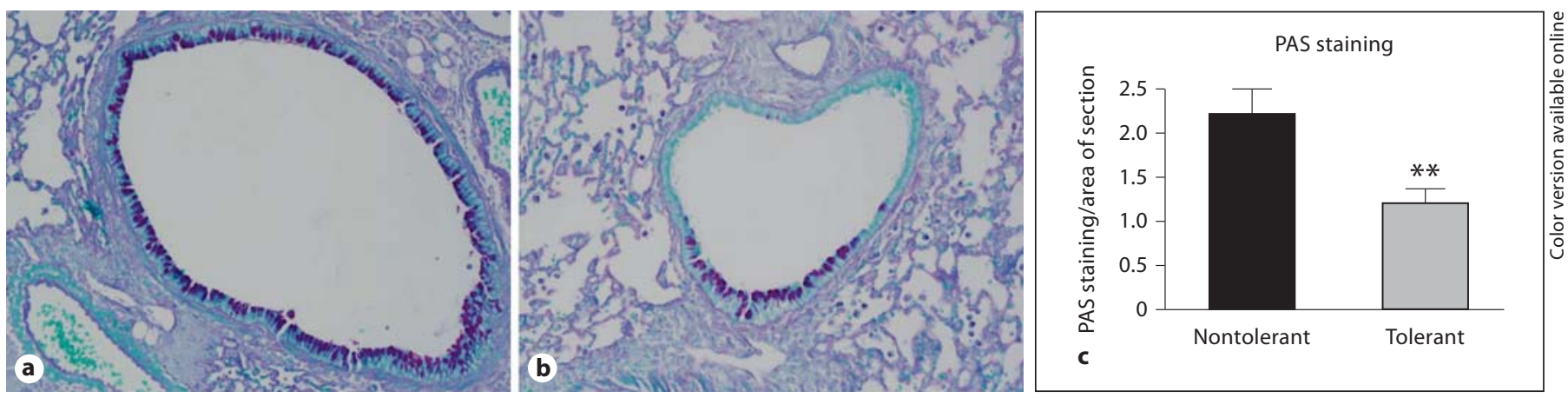

Fig. 3. PAS staining and quantification. Representative images of PAS stained nontolerant (a) and tolerant mice (b) $24 \mathrm{~h}$ after final allergen challenge. c The amount of positive PAS staining was quantified using NIH ImageJ software and expressed as area of
PAS staining per area of the entire lung section. Data are presented as mean \pm SEM ( $n=4$ mice per group, per experiment; combination of 3 separate experiments). ${ }^{* *} \mathrm{p}<0.01$ compared to nontolerant group. leukotrienes are not primarily responsible for AHR in this model (fig. 2c).

PAS staining was performed in lung sections harvested at $24 \mathrm{~h}$ after final challenge. We observed decreased mucus staining in the airway epithelial cells of LPS-tolerant mice compared to the nontolerant group (fig. 3a, b). Quantification of this staining using the NIH ImageJ software confirmed these observations, showing significantly less PAS staining in the tolerant lungs (fig. 3c).

\section{Eosinophil Influx and Eosinophil-Specific Chemokine Production}

Eosinophil infiltration is a cardinal feature of the late phase of the asthmatic response [26]. Absolute numbers of eosinophils in the BAL fluid of LPS-tolerant mice were significantly reduced (fig. 4a). This was accompanied by a concomitant decrease in eotaxin-1 (CCL11) and eotaxin-2 (CCL24) concentrations in the BAL fluid (fig. 4b, c). In order to rule out the possibility that reduced BAL chemokine expression was causing eosinophils to sequester in the lung parenchyma, we measured EPO activity as an indicator of eosinophil presence in the lung tissue. EPO activity $24 \mathrm{~h}$ after final challenge, as well as lung homogenate CCL11 and CCL24 concentrations were significantly decreased in LPS-tolerant mice (fig. 4d-f). No difference in RANTES (CCL5) production was measured (data not shown).

Eosinophil numbers in the parenchyma were further confirmed by Congo red staining of paraffin-embedded lung sections. Eosinophils were identified by cellular and nuclear morphology, as well as pink cytoplasmic amyloid staining. Representative digital images of nontolerant and tolerant lungs show an apparent reduction in eosino- phil numbers in the tolerant lungs (fig. 5a, b). Quantification of these sections clearly demonstrates decreased numbers of eosinophils in the lungs of LPS-tolerant mice (fig. 5c).

\section{Th1 and Th2 Cytokine Production in BAL Fluid}

Asthma is largely characterized as a Th2-mediated disease characterized by high concentrations of IL- 4 and IL-5, and low levels of IFN $\gamma$ [27]. We investigated whether LPS tolerance alters the production of Th1 and Th2 cytokines, possibly skewing the inflammatory response to one mediated primarily by IFN $\gamma$. We found a slight increase in BAL concentrations of IFN $\gamma$, IL-4, IL-5 and IL13 in LPS-tolerant mice at 2 and $24 \mathrm{~h}$ after final challenge, although this did not reach statistical significance (fig. 6). Also, no statistical difference was seen in BAL IL-12 (data not shown). While LPS tolerance protects against eosinophilia, and AHR, LPS-tolerant mice are still capable of robust cytokine production.

\section{Antibody Production in Response to Allergen \\ Sensitization and Challenge}

Cross-linking of allergen-specific IgE on the surface of mast cells causes degranulation, and release of histamines, cytokines, and leukotrienes, which can cause subsequent AHR and epithelial damage [28, 29]. Plasma levels of total IgE were significantly decreased in LPS-tolerant mice, and were comparable to those measured in naïve animals (fig. 7a). A slight decrease in CRA-specific IgE was measured in LPS-tolerant mice receiving immunization only (fig. 7b). We further sought to determine whether LPS tolerance suppressed the production of IgG1, associated with Th2 responses, and IgG2a, associ- 
Fig. 4. Eosinophil recruitment and production of eosinophil-specific chemokines in response to allergen challenge. Cytospin preparations from cells isolated from the BAL fluid were made and 300 cell differential counts performed to determine the absolute numbers of eosinophils at $24 \mathrm{~h}$ after final challenge (a). Concentrations of the chemokines CCL11 (b) and CCL24 (c) in the BAL fluid were measured by standard ELISA. d Eosinophil peroxidase activity was measured in the lung tissue after BAL at $24 \mathrm{~h}$ after final challenge. Concentrations of CCL11 (e) and CCL24 (f) in the lung homogenate (LH) were assayed by standard ELISA. Data are presented as the mean \pm SEM $(n=4$ mice per group, per experiment; combination of 3 separate experiments). ${ }^{*} \mathrm{p}<0.05,{ }^{* *} \mathrm{p}<$ 0.0001 compared to nontolerant group.
Eosinophils in BAL

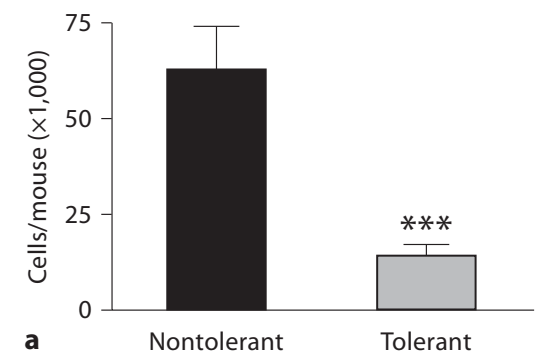

Eotaxin-1 (CCL11) BAL

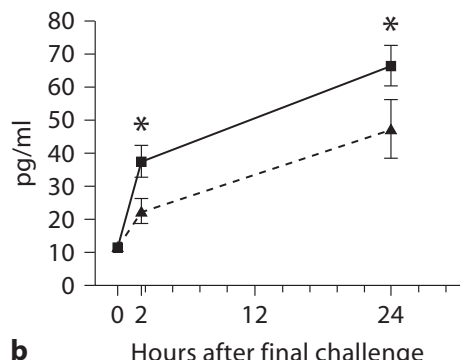

b

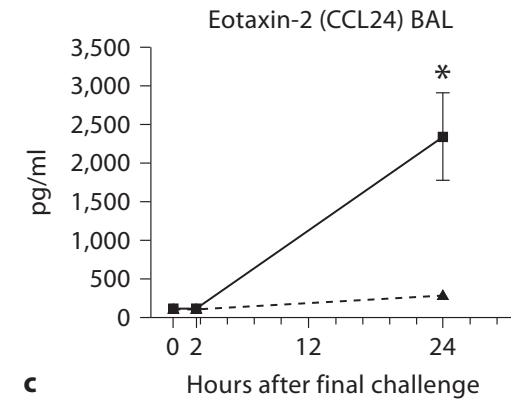
Hours after final challenge
Eosinophils peroxidase activity

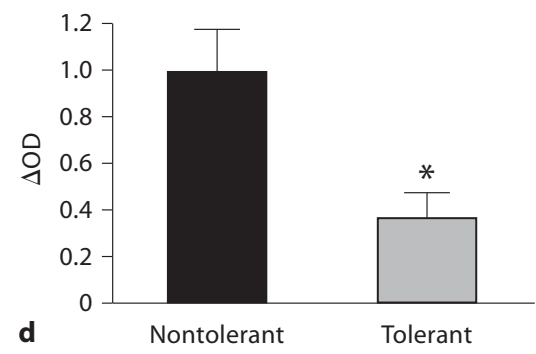

Eotaxin-1 (CCL11) LH

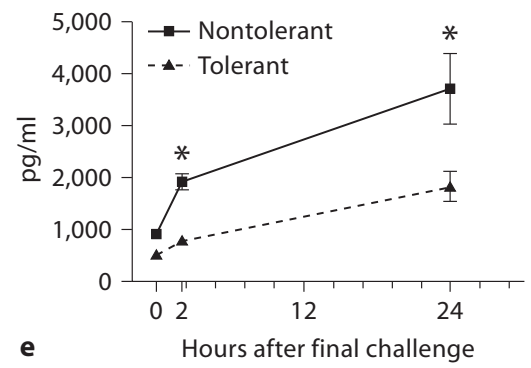

Eotaxin-2 (CCL24) LH

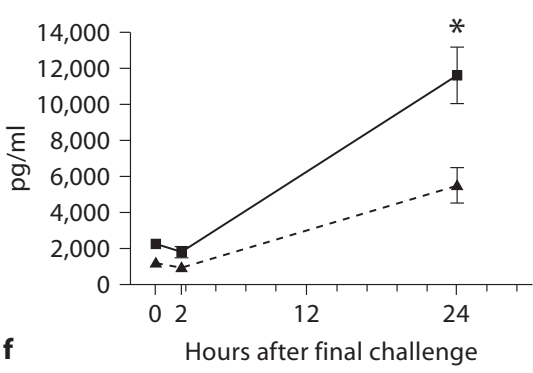

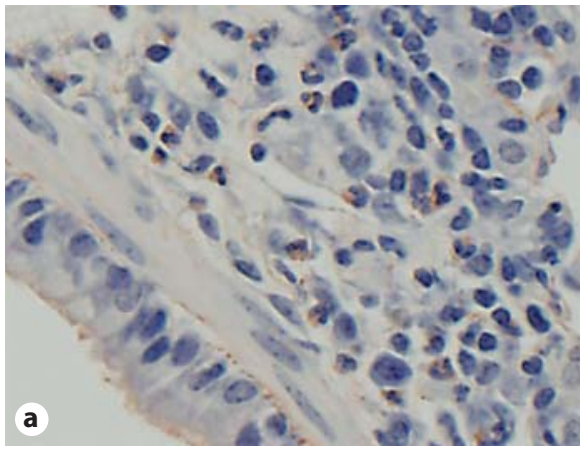

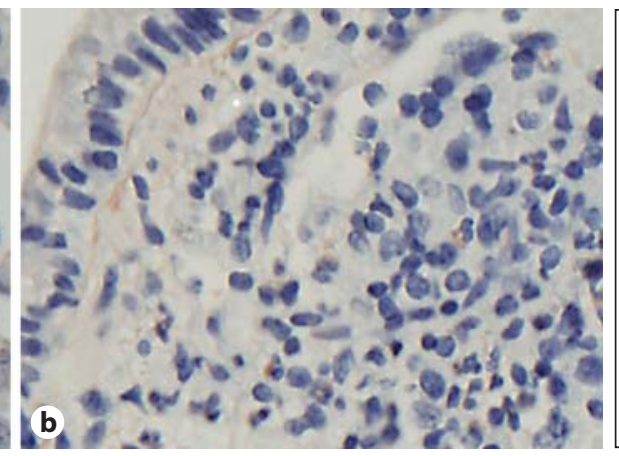

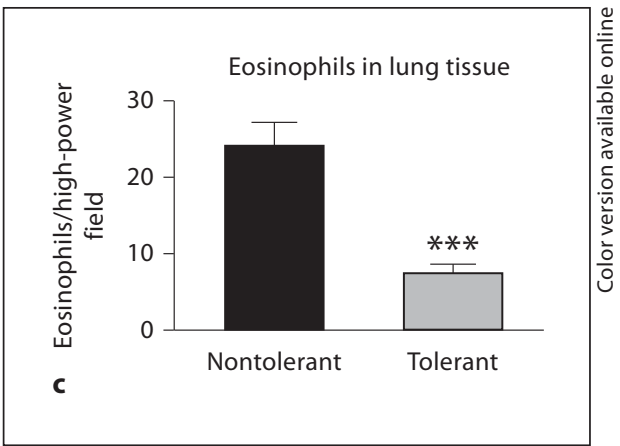

Fig. 5. Eosinophil staining and quantification of lung sections. Representative images of paraffin sections from nontolerant (a) and tolerant (b) mice at $24 \mathrm{~h}$ after final allergen challenge were stained with Congo red. Eosinophils were identified by morphol- ogy and red cytoplasmic staining. c Number of eosinophils per high-power field was quantified. Data are presented as mean \pm SEM ( $n=4$ mice per group, per experiment; combination of 3 separate experiments). ${ }^{* * *} \mathrm{p}<0.001$ compared to nontolerant group. 
Fig. 6. Th1 and Th2 cytokine production in BAL fluid at $24 \mathrm{~h}$ after final allergen challenge. Th1 cytokine IFN $\gamma(\mathbf{a})$ and Th2 cytokines, IL-4 (b), IL-5 (c) and IL-13 (d) were assayed by ELISA. Data are presented as the mean \pm SEM $(n=4$ mice per group, per experiment; combination of 3 separate experiments).

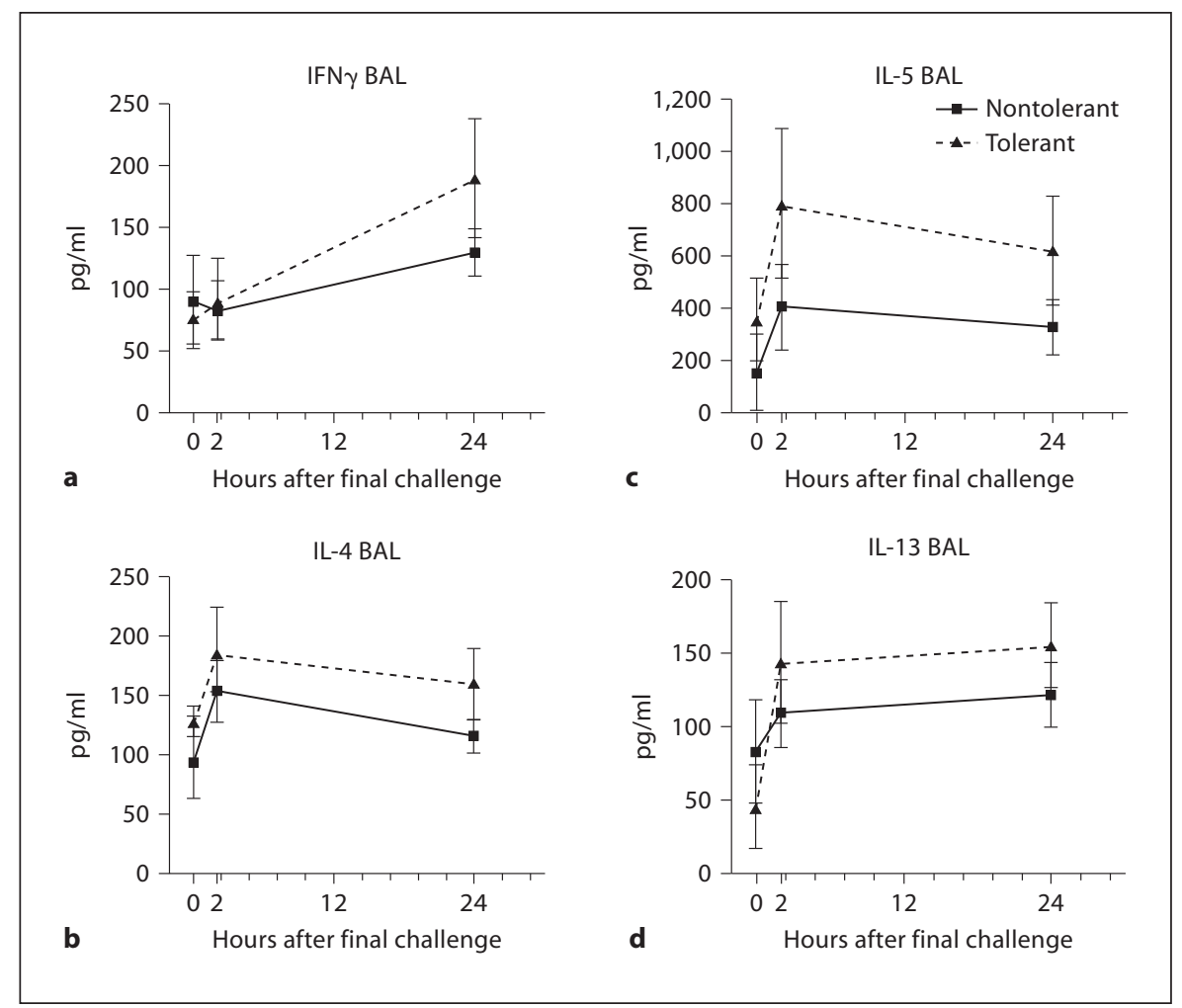

ated with a Th1 phenotype [30]. Total IgG1 was significantly increased in immunized-only mice, but no difference in IgG1 or IgG2a was measured after immunization and challenge (fig. $7 c, d$ ). This indicates that LPS tolerance induces specific inhibition of IgE in this model.

\section{Discussion}

The effect of activators of the innate immune system on the development of the adaptive response to allergen has become an important focus of investigation. Epidemiological studies have produced conflicting results with regard to the effect of repeated LPS inhalation. Animal models have correlated high-dose LPS exposure with decreased allergen sensitization, whereas low levels of LPS seem to potentiate sensitization [31, 32]. Wang et al. [33] showed that intranasal exposure to LPS in neonatal mice protected from ovalbumin sensitization and resulted in increased regulatory $\mathrm{T}$ cell numbers. Further, it has been shown that TLR4 signaling is required for the development of antigenic tolerance in previously sensitized mice, but is not required for the development of sensitization [34]. In a recent rodent study, administration of a mono- clonal TLR4 agonist prior to ovalbumin sensitization significantly attenuated airway eosinophilia, mucus production and AHR [35]. Our novel findings demonstrate that protection from allergen sensitization can be directly attributed to pulmonary tolerance to LPS. However, we employed a crude LPS preparation, and our allergen mixture contains many innate immune-activating compounds. Therefore, it is likely that this phenomenon is mediated by TLR4 as well as other pattern recognition receptors.

In this model, LPS tolerance was induced by four consecutive days of high-dose intratracheal LPS administration, followed by induction of asthma by intratracheal exposure to CRA. Few investigators use intratracheal delivery of environmentally relevant allergens for the study of asthma-like inflammation [36-38]. Most models utilize ovalbumin, which is not an environmental allergen, and employ an average of 6 exposures and a total of 2,000 $\mu \mathrm{g}$ of allergen, while our model requires 3 exposures and a total of only $4 \mu \mathrm{g}$ of allergen [39-41]. This is potentially explained by the inherent protease activity present in cockroach frass and gastrointestinal proteins, which may facilitate antigen uptake by dendritic cells in the lung [42, 43]. The ability to induce asthma-like pulmonary inflam- 


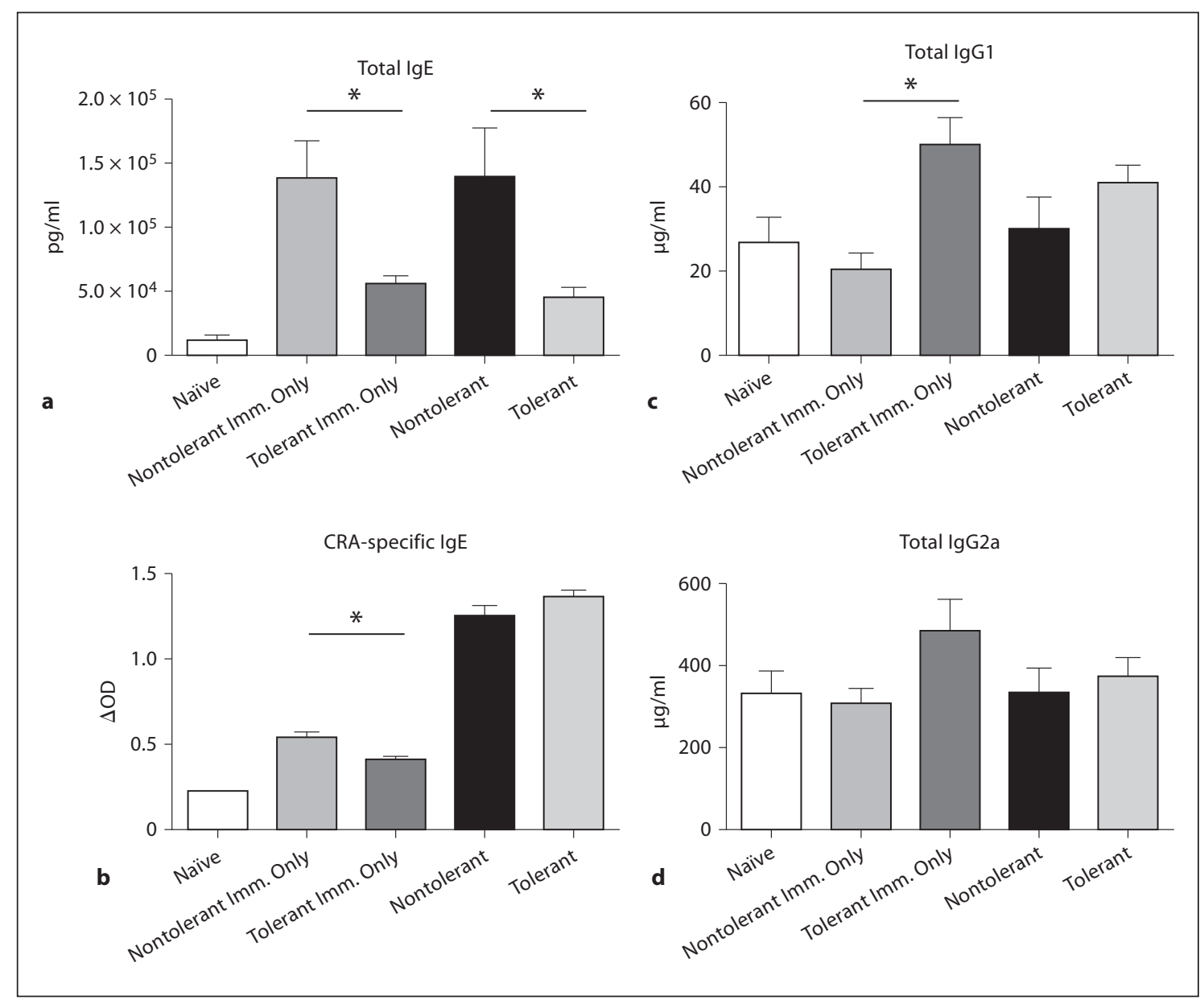

Fig. 7. Plasma antibody production in response to allergen sensitization and challenge. IgE (a), CRA-specific IgE (b), IgG1 (c) and IgG2a (d) were measured in plasma collected at day 22 after sensitization by standard ELISA. The Imm. Only group received CRA sensitization, but no challenge on days 14 or 21 . Data are presented as the mean \pm SEM ( $n=4$ mice per group, per experiment; combination of 3 separate experiments). ${ }^{*} \mathrm{p}<$ 0.05 compared to naïve mice as measured by Student's t test.

mation with relatively low concentrations of allergen may lie not only in the use of an environmentally relevant allergen, but also in the substantial LPS contamination naturally present in the allergen preparation. Therefore, our model recapitulates the environmental setting in which LPS contamination is ubiquitous. Our model also demonstrates the physiologically relevant adjuvant effects of LPS, as other compounds, such as Freund's adjuvant can cause artificial skewing toward a Th2 immune response [21].

The current findings demonstrate that the modulation of innate immunity induced by LPS tolerance is transient. CXC chemokine production and neutrophil recruitment are not affected 21 days after LPS tolerance was induced (fig. 1). Further, decreases in TNF $\alpha$, a hallmark feature of the LPS-tolerant phenotype, are no longer present. Immune activation induced by LPS tolerance is protective against allergen sensitization, while one exposure to lowdose LPS, concomitant with sensitization (nontolerant group) potentiates the development of asthma.

Our data demonstrate a significant decrease in CRAspecific IgE in LPS-tolerant mice receiving only immunization, but no difference is measured in mice receiving both allergen challenges, while an opposite trend was measured in total IgG1. This can be partially explained in that the effects of LPS tolerance are no longer present at the time of the first allergen challenge (day 14). Therefore, antibody production in response to the first chal- 
lenge is equivalent between groups. The differential regulation of these two isotypes (increased IgG1 and decreased $\operatorname{IgE})$ may be mediated by the cytokine milieu present in the microenvironment of naïve B cells. Previous studies have reported that TGF $\beta$ and IL-10 can inhibit IL-4-mediated class switch recombination to IgE, a role for TGF $\beta$ in mediating endotoxin tolerance has been confirmed [44-46]. TGF $\beta$ was also shown to have no effect on IL-4mediated class switch to IgG1 [47]. Therefore, while mediators such as TGF $\beta$ may inhibit IgE production, other cytokines such as IFN $\gamma$ may drive IgG1 production [47]. Our data also demonstrated a significant reduction in total IgE in immunized-only LPS-tolerant mice, as well as those receiving both allergen challenges. This is likely due to the production of polyclonal IgE in response to LPS [48]. When LPS signaling is attenuated (LPS tolerance), total IgE production is inhibited.

We also determined that the mechanism underlying decreased eosinophilia is the reduction in CCL11 and CCL24 in both the BAL fluid and organ homogenate. We hypothesized that if the lack of eosinophils in the alveolar space and lung tissue was purely the result of a defective chemotactic gradient, increased numbers of circulating eosinophils would be present. Analysis of the peripheral blood showed no differences in circulating eosinophils in nontolerant mice compared to the LPS-tolerant group (data not shown). Further, IL-5 is a key mediator in eosinophil activation and egress from the bone marrow into sites of inflammation [49]. Plasma IL-5 levels were below the limit of detection (data not shown) of our ELISA (13.7 $\mathrm{pg} / \mathrm{ml}$ ); however, this does not rule out the possibility that concentrations below this limit are sufficient to mobilize eosinophils.

LPS-tolerant mice were protected from AHR, as well as airway resistance. We observed a dissociation between methacholine-induced airways hyperresponsiveness and cysteinyl leukotrienes. Our earlier studies also showed a similar protection from AHR and concomitant increases in cysteinyl leukotrienes [50]. We found that protection from methacholine-induced AHR was mediated through a reduction in $\mathrm{M} 2$ and $\mathrm{M} 3$ muscarinic receptor expression [51]. It is of importance to determine whether muscarinic receptor downregulation lasts up to 21 days after LPS tolerance induction. The robust production of cysteinyl leukotrienes suggests that mast cell function is not impaired in the tolerant mice. Therefore, it is unlikely that the protection from AHR is mediated by the observed reduction in IgE. This dissociation between IgE and AHR has been demonstrated in mast cell and B cell-deficient mice $[52,53]$. It is possible that the lack of mucus production seen in LPS-tolerant lungs contributes to the reduced airway resistance $[54,55]$. Further, airway sensitization has been shown to induce a strong Th17 response leading to robust AHR [56]. We measured BAL levels of IL-17 and found no significant difference between groups at 2 or $24 \mathrm{~h}$ after final challenge (data not shown).

Taken together, our data show that prior inhalation of high doses of LPS protects against airway eosinophilia, AHR, mucus production and IgE. Further, these studies show that optimal allergen sensitization requires innate immune activation, and that this transient modulation of the innate immune response can have lasting effects on adaptive immunity. Further epidemiological studies are needed to determine whether lungs of individuals exposed to high levels of LPS are refractory to further LPS stimulation, which may confer protection against allergen sensitization.

\section{Acknowledgements}

The authors have no conflicting financial interests. This work was supported by National Institutes of Health Grant R01 ES013528.

S.N. designed and executed the experiments, and wrote the manuscript. J.B. and J.K. assisted with conducting the experiments, interpreting the data and reviewing the manuscript. W.C. assisted with the Flexivent measurements and reviewed the manuscript. D.R. assumed overall responsibility for the experimental design and manuscript preparation. All authors read and approved the final manuscript.

\section{References}

1 Bochner BS, Undem BJ, Lichtenstein LM: Immunological aspects of allergic asthma. Annu Rev Immunol 1994;12:295-335.

- Schroder NW, Arditi M: The role of innate immunity in the pathogenesis of asthma: Evidence for the involvement of toll-like receptor signaling. J Endotoxin Res 2007;13:305-312.

$\checkmark 3$ Akira S, Uematsu S, Takeuchi O: Pathogen recognition and innate immunity. Cell 2006 124:783-801.

\footnotetext{
4 Kim YK, Oh SY, Jeon SG, Park HW, Lee SY, Chun EY, Bang B, Lee HS, Oh MH, Kim YS, Kim JH, Gho YS, Cho SH, Min KU, Kim YY, Zhu Z: Airway exposure levels of lipopolysaccharide determine type 1 versus type 2 experimental asthma. J Immunol 2007;178: 5375-5382.

$\checkmark 5$ Horner AA: Toll-like receptor ligands and atopy: a coin with at least two sides. J Allergy Clin Immunol 2006;117:1133-1140.
} 
6 von Mutius E: Allergies, infections and the hygiene hypothesis - the epidemiological evidence. Immunobiology 2007;212:433-439.

7 Frew AJ: Advances in environmental and occupational diseases 2004. J Allergy Clin Immunol 2005;115:1197-1202.

$>8$ Liebers V, Raulf-Heimsoth M, Bruning T: Health effects due to endotoxin inhalation. Arch Toxicol 2008;82:203-210.

9 Medvedev AE, Sabroe I, Hasday JD, Vogel SN: Tolerance to microbial TLR ligands: molecular mechanisms and relevance to disease. J Endotoxin Res 2006;12:133-150.

-10 Natarajan S, Kim J, Remick DG: Acute pulmonary lipopolysaccharide tolerance decreases TNF-alpha without reducing neutrophil recruitment. J Immunol 2008;181:84028408.

-11 Natarajan S, Kim J, Remick DG: Chronic pulmonary LPS tolerance induces selective immunosuppression while maintaining the neutrophilic response. Shock 2010;33:162169.

-12 Gavett SH, O’Hearn DJ, Li X, Huang SK, Finkelman FD, Wills-Karp M: Interleukin 12 inhibits antigen-induced airway hyperresponsiveness, inflammation, and Th2 cytokine expression in mice. J Exp Med 1995;182: 1527-1536.

-13 McGraw DW, Almoosa KF, Paul RJ, Kobilka BK, Liggett SB: Antithetic regulation by beta-adrenergic receptors of $\mathrm{Gq}$ receptor signaling via phospholipase $c$ underlies the airway beta-agonist paradox. J Clin Invest 2003; 112:619-626.

- 14 Campbell JD, Buckland KF, McMillan SJ, Kearley J, Oldfield WL, Stern LJ, Gronlund $H$, van Hage $M$, Reynolds CJ, Boyton RJ, Cobbold SP, Kay AB, Altmann DM, Lloyd CM, Larche M: Peptide immunotherapy in allergic asthma generates IL-10-dependent immunological tolerance associated with linked epitope suppression. J Exp Med 2009; 206:1535-1547.

-15 Gilchrist M, Henderson WR Jr, Clark AE, Simmons RM, Ye X, Smith KD, Aderem A: Activating transcription factor 3 is a negative regulator of allergic pulmonary inflammation. J Exp Med 2008;205:2349-2357.

-16 Schneider T, Issekutz AC: Quantitation of eosinophil and neutrophil infiltration into rat lung by specific assays for eosinophil peroxidase and myeloperoxidase: application in a brown Norway rat model of allergic pulmonary inflammation. J Immunol Methods 1996;198:1-14

-17 Nemzek JA, Siddiqui J, Remick DG: Development and optimization of cytokine ELISAs using commercial antibody pairs. J Immunol Methods 2001;255:149-157.

- 18 Kim J, Merry AC, Nemzek JA, Bolgos GL, Siddiqui J, Remick DG: Eotaxin represents the principal eosinophil chemoattractant in a novel murine asthma model induced by house dust containing cockroach allergens. J Immunol 2001;167:2808-2815.
19 Pasare C, Medzhitov R: Toll-dependent control mechanisms of CD4 $\mathrm{T}$ cell activation. Immunity 2004;21:733-741.

20 Grouls V, Helpap B: Selective staining of eosinophils and their immature precursors in tissue sections and autoradiographs with Congo red. Stain Technol 1981;56:323-325.

21 Shibaki A, Katz SI: Induction of skewed TH1/TH2 T-cell differentiation via subcutaneous immunization with Freund's adjuvant. Exp Dermatol 2002;11:126-134.

22 Fitting C, Dhawan S, Cavaillon JM: Compartmentalization of tolerance to endotoxin. Infect Dis 2004;189:1295-1303.

23 Virca GD, Kim SY, Glaser KB, Ulevitch RJ: Lipopolysaccharide induces hyporesponsiveness to its own action in raw 264.7 cells. J Biol Chem 1989;264:21951-21956.

24 West MA, Heagy W: Endotoxin tolerance: a review. Crit Care Med 2002;30:S64-S73.

25 Vaickus LJ, Bouchard J, Kim J, Natarajan S, Remick DG: Assessing pulmonary pathology by detailed examination of respiratory function. Am J Pathol 2010;177:1861-1869.

26 Heinecke JW: Eosinophil-dependent bromination in the pathogenesis of asthma. J Clin Invest 2000;105:1331-1332.

27 Holgate ST: Pathogenesis of asthma. Clin Exp Allergy 2008;38:872-897.

28 Stone KD, Prussin C, Metcalfe DD: IgE, mast cells, basophils, and eosinophils. J Allergy Clin Immunol 2010;125:S73-S80.

29 Bradding P, Walls AF, Holgate ST: The role of the mast cell in the pathophysiology of asthma. J Allergy Clin Immunol 2006;117: 1277-1284.

30 Geha RS, Jabara HH, Brodeur SR: The regulation of immunoglobulin e class-switch recombination. Nat Rev Immunol 2003;3:721732.

31 Tulic MK, Wale JL, Holt PG, Sly PD: Modification of the inflammatory response to allergen challenge after exposure to bacterial lipopolysaccharide. Am J Respir Cell Mol Biol 2000;22:604-612.

32 Blumer N, Herz U, Wegmann M, Renz H Prenatal lipopolysaccharide-exposure prevents allergic sensitization and airway inflammation, but not airway responsiveness in a murine model of experimental asthma. Clin Exp Allergy 2005;35:397-402.

-33 Wang Y, McCusker C: Neonatal exposure with LPS and/or allergen prevents experimental allergic airways disease: development of tolerance using environmental antigens. J Allergy Clin Immunol 2006;118:143151.

34 Hollingsworth JW, Whitehead GS, Lin KL, Nakano H, Gunn MD, Schwartz DA, Cook DN: TLR4 signaling attenuates ongoing allergic inflammation. J Immunol 2006;176: 5856-5862.
35 Matsushita H, Ohta S, Shiraishi H, Suzuki S, Arima K, Toda S, Tanaka H, Nagai H, Kimoto M, Inokuchi A, Izuhara K: Endotoxin tolerance attenuates airway allergic inflammation in model mice by suppression of the T-cell stimulatory effect of dendritic cells. Int Immunol 2010;22:739-747.

>36 Page K, Ledford JR, Zhou P, Wills-Karp M: A TLR2 agonist in German cockroach frass activates MMP-9 release and is protective against allergic inflammation in mice. J Immunol 2009; 183:3400-3408.

37 Lajoie S, Lewkowich IP, Suzuki Y, Clark JR, Sproles AA, Dienger K, Budelsky AL, WillsKarp M: Complement-mediated regulation of the IL-17a axis is a central genetic determinant of the severity of experimental allergic asthma. Nat Immunol 2010;11:928935.

38 Page K, Ledford JR, Zhou P, Dienger K, Wills-Karp M: Mucosal sensitization to German cockroach involves protease-activated receptor-2. Respir Res 2010;11:62.

-39 Sung S, Rose CE, Fu SM: Intratracheal priming with ovalbumin- and ovalbumin 323339 peptide-pulsed dendritic cells induces airway hyperresponsiveness, lung eosinophilia, goblet cell hyperplasia, and inflammation. J Immunol 2001;166:1261-1271.

40 Kohl J, Baelder R, Lewkowich IP, Pandey MK, Hawlisch H, Wang L, Best J, Herman NS, Sproles AA, Zwirner J, Whitsett JA, Gerard C, Sfyroera G, Lambris JD, Wills-Karp $\mathrm{M}$ : A regulatory role for the $\mathrm{C} 5 \mathrm{a}$ anaphylatoxin in type 2 immunity in asthma. J Clin Invest 2006;116:783-796.

41 Farraj AK, Harkema JR, Jan TR, Kaminski NE: Immune responses in the lung and local lymph node of A/J mice to intranasal sensitization and challenge with adjuvant-free ovalbumin. Toxicol Pathol 2003;31:432-447.

42 Roche N, Chinet TC, Huchon GJ: Allergic and nonallergic interactions between house dust mite allergens and airway mucosa. Eur Respir J 1997;10:719-726.

-43 Arizmendi NG, Abel M, Mihara K, Davidson C, Polley D, Nadeem A, El Mays T, Gilmore BF, Walker B, Gordon JR, Hollenberg MD, Vliagoftis $\mathrm{H}$ : Mucosal allergic sensitization to cockroach allergens is dependent on proteinase activity and proteinase-activated receptor-2 activation. J Immunol 2011;186: 3164-3172.

44 Taher YA, van Esch BC, Hofman GA, Henricks PA, van Oosterhout AJ: 1alpha,25-dihydroxyvitamin $\mathrm{D}_{3}$ potentiates the beneficial effects of allergen immunotherapy in a mouse model of allergic asthma: role for IL10 and TGF-beta. J Immunol 2008; 180:52115221.

45 Punnonen J, Cocks BG, de Vries JE: Il-4 induces germ-line IGE heavy chain gene transcription in human fetal pre-B cells: evidence for differential expression of functional IL-4 and IL-13 receptors during B cell ontogeny. J Immunol 1995;155:4248-4254. 
-46 Sly LM, Rauh MJ, Kalesnikoff J, Song CH, Krystal G: LPS-induced upregulation of ship is essential for endotoxin tolerance. Immunity 2004;21:227-239.

47 Deenick EK, Hasbold J, Hodgkin PD: Decision criteria for resolving isotype switching conflicts by B cells. Eur J Immunol 2005;35: 2949-2955.

-48 Litinskiy MB, Nardelli B, Hilbert DM, He B, Schaffer A, Casali P, Cerutti A: DCs induce CD40-independent immunoglobulin class switching through BLyS and APRIL. Nat Immunol 2002;3:822-829.

49 Sugita K, Kabashima K, Sakabe JI, Yoshiki R, Tanizaki H, Tokura Y: FTY720 regulates bone marrow egress of eosinophils and modulates late-phase skin reaction in mice. Am J Pathol 2010;177:1881-1887.
50 Natarajan S, Kim J, Bouchard J, Cruikshank W, Remick DG: Reducing LPS content in cockroach allergens increases pulmonary cytokine production without increasing inflammation: a randomized laboratory study. BMC Pulm Med 2011;11:12.

51 Natarajan S, Kim J, Remick DG: Chronic pulmonary LPS tolerance induces selective immunosuppression while maintaining the neutrophilic response. Shock 2010;33:162169.

52 Noviski N, Brewer JP, Skornik WA, Galli SJ, Drazen JM, Martin TR: Mast cell activation is not required for induction of airway hyperresponsiveness by ozone in mice. J Appl Physiol 1999;86:202-210.

53 Hamelmann E, Tadeda K, Oshiba A, Gelfand EW: Role of IGE in the development of allergic airway inflammation and airway hyperresponsiveness - a murine model. Allergy 1999;54:297-305.
54 Agrawal A, Rengarajan S, Adler KB, Ram A, Ghosh B, Fahim M, Dickey BF: Inhibition of mucin secretion with MARCKS-related peptide improves airway obstruction in a mouse model of asthma. J Appl Physiol 2007;102: 399-405.

55 Vaickus LJ, Bouchard J, Kim J, Natarajan S, Remick DG: Assessing pulmonary pathology by detailed examination of respiratory function. Am J Pathol 2010;177:1861-1869.

56 Wilson RH, Whitehead GS, Nakano H, Free ME, Kolls JK, Cook DN: Allergic sensitization through the airway primes TH17-dependent neutrophilia and airway hyperresponsiveness. Am J Respir Crit Care Med 2009;180:720-730. 